\title{
Rotatividade de Pessoal: Pesquisa com Profissionais de Empresas Brasileiras de Desenvolvimento de Software
}

\author{
Guilherme L. Frufrek ${ }^{1}$, Luciano T. E. Pansanato ${ }^{1}$ \\ ${ }^{1}$ Departamento Acadêmico de Computação \\ Universidade Tecnológica Federal do Paraná (UTFPR) - Cornélio Procópio - Brazil \\ frufrek@utfpr.edu.br, luciano@utfpr.edu.br
}

\begin{abstract}
Employee turnover is one of the major challenges for many software development companies. This paper presents a survey to identify the main causes and effects of employee turnover among professionals of Brazilian software development companies. This survey also investigated management strategies applied to minimize employee turnover and its effects. The analysis of data from 67 respondents was conducted through descriptive statistics and inferential statistics. The results indicate that lack of professional recognition, lack of wage policy, lack of organization's involvement, and personal expectation not achieved within the company influences the decision of professionals to leave the company and they can contribute decisively in rates of employee turnover. The results also indicate other aspects that are important for turnover intention. The company must be concerned with factors that can motivate the employee to stay with the company, such as career plan, work environment, promotion by performance, and periodic training.
\end{abstract}

Resumo. A rotatividade de pessoal é um dos principais desafios para muitas empresas de desenvolvimento de software. Neste artigo é apresentada uma pesquisa de opinião para identificar as principais causas e efeitos da rotatividade de pessoal entre profissionais de empresas brasileiras de desenvolvimento de software. As estratégias de gestão empregadas para minimizar a rotatividade de pessoal e seus efeitos também foram investigadas. A análise dos dados de 67 respondentes foi realizada por meio de estatística descritiva e estatística inferencial. Os resultados indicaram que a falta de reconhecimento profissional, falta de política salarial, falta de comprometimento da organização e insatisfação decorrente de expectativa não alcançada influenciam a decisão dos profissionais de sair da empresa e podem contribuir decisivamente nas taxas de rotatividade de pessoal. Os resultados também indicaram outros aspectos que são importantes para a intenção de rotatividade. A empresa deve se preocupar com fatores que podem motivar a permanência do funcionário, como plano de carreira, ambiente de trabalho, promoção por desempenho e treinamento periódico.

\section{Introdução}

A competição intensa por profissionais de Tecnologia da Informação (TI) entre as empresas cria situações que geram um fenômeno conhecido como rotatividade de pessoal (Calisir et al. 2011; Joseph et al. 2007). A rotatividade de pessoal (employee 
turnover) é a movimentação de profissionais entre as empresas (Abbasi e Hollman 2000). Essa movimentação pode ser voluntária, quando o próprio funcionário deixa a empresa, ou involuntária, quando a empresa decide não manter o funcionário.

As falhas no gerenciamento de pessoal, a baixa disponibilidade e a demanda crescente de profissionais de TI são fatores que influenciam os profissionais a migrarem para outras empresas (Ang e Slaughter 2004). O impacto dessa migração para as empresas de desenvolvimento de software é grande, pois possuem dependência dos profissionais envolvidos em seus projetos, principalmente pelo fato da alta especialização destes profissionais e da sua substituição não ser imediata.

Os problemas com a alta rotatividade de pessoal são constantes nas empresas de desenvolvimentos de software (Yu et al. 2010). Os prejuízos e atrasos decorrentes podem consumir uma fração significativa do lucro esperado de um projeto (Felps et al. 2009). Portanto, para as empresas da indústria de software é importante conhecer as causas da rotatividade e as possíveis estratégias de gestão que podem ser implantadas para que não se torne um problema. Essas estratégias abrangem ações ou práticas de gestão que são definidas no nível gerencial de uma organização.

A importância desse conhecimento (sobre rotatividade de pessoal) para executivos, gerentes, líderes de projeto, entre outros profissionais, motiva e justifica esta pesquisa entre profissionais de empresas brasileiras de desenvolvimento de software. Esses profissionais constituem um grupo importante considerando que o crescimento nesta década da área de TI permanecerá acima de 10\% ao ano no Brasil contra uma expectativa mundial um pouco superior a 3\% (dados do Ministério de Ciência e Tecnologia).

$\mathrm{Na}$ revisão dos trabalhos relacionados, apenas Carvalho (2012) e Ress et al. (2010) apresentam pesquisas realizadas no contexto brasileiro. Carvalho (2012) realizou um estudo de caso para analisar os efeitos da rotatividade na produtividade de processos de software tradicionais e híbridos por meio de coleta de dados de projetos em uma empresa de desenvolvimento de software. Ress et al. (2010) investigou o uso da gestão de conhecimento como fator de moderação do impacto da rotatividade no desempenho dos projetos por meio de estudos de casos com as equipes de desenvolvimento de software de duas empresas do segmento financeiro.

Os trabalhos relacionados que apresentam pesquisas no contexto brasileiro abordam fatores específicos relacionados com a rotatividade. O objetivo da pesquisa apresentada neste artigo foi identificar quais são as principais causas e efeitos da rotatividade de pessoal, e estratégias de gestão para minimizar a rotatividade e seus efeitos, segundo a opinião de profissionais de empresas brasileiras de desenvolvimento de software. Dessa forma, o objetivo foi identificar os fatores que caracterizam a rotatividade no contexto proposto.

As causas, efeitos e estratégias de gestão consideradas para a pesquisa foram identificadas a partir de trabalhos relacionados encontrados na literatura. A revisão dos trabalhos da literatura é apresentada na Seção 2, na qual são descritas as questões relacionadas e a abordagem sistemática adotada para a sua condução. A partir da análise de 39 trabalhos, foram selecionadas 14 causas, 08 efeitos e 08 estratégias de gestão, que 
são apresentadas com uma breve descrição do seu relacionamento com a rotatividade de pessoal.

A metodologia da pesquisa é apresentada na Seção 3. O método escolhido foi a pesquisa de opinião e o questionário foi utilizado como técnica de coleta de dados. As seguintes etapas consideradas para a pesquisa de opinião são apresentadas: elaboração do questionário; pré-teste do questionário; seleção da amostra; aplicação do questionário; e análise e interpretação dos dados. O questionário foi enviado para 40 empresas brasileiras de desenvolvimento de software. Ao todo, 67 profissionais responderam o questionário.

Na Seção 4, os resultados são apresentados e discutidos. A análise dos dados foi realizada por meio de estatística descritiva e estatística inferencial. A caracterização dos respondentes e de suas empresas é apresentada para ressaltar a relevância da amostra obtida. Na sequência são apresentados os resultados relacionados às causas/efeitos e estratégias de gestão. Ao final, são apresentadas algumas comparações entre grupos de respondentes. Nessa comparação, foram considerados grupos de respondentes com e sem cargo gerencial, de empresas com menos e mais de 50 funcionários, de empresas com processo de desenvolvimento de software definido e com processo parcialmente definido, e de empresas com e sem certificação de melhoria de processo de software.

As ameaças à validade dos resultados foram discutidas na Seção 5 . O objetivo dessa discussão é apresentar como foram minimizados os efeitos de prováveis problemas que podem influenciar a validade dos resultados. Na Seção 6, as conclusões e os trabalhos futuros são apresentadas.

\section{Trabalhos Relacionados}

Para realizar uma revisão dos trabalhos relacionados de maneira mais sistemática, o modelo de pesquisa seguido por Mikropoulos e Natsis (2011) e a metodologia de revisão proposta por Kitchenham (2004) foram combinados. Como resultado dessa combinação, as seguintes etapas foram definidas: planejamento da revisão; condução da revisão; e apresentação dos resultados da revisão.

$\mathrm{Na}$ etapa de planejamento da revisão, as seguintes Questões de Pesquisa (QP) foram formuladas para identificar os trabalhos relacionados:

- QP1: Quais trabalhos analisam a rotatividade de pessoal em empresas de desenvolvimento de software?

- QP2: Quais as causas e efeitos da rotatividade de pessoal?

- QP3: Quais as estratégias de gestão para minimizar a rotatividade de pessoal e seus efeitos?

$\mathrm{Na}$ etapa de condução da revisão, as seguintes atividades foram realizadas: definir critérios de inclusão; realizar a pesquisa por trabalhos; avaliar a qualidade e selecionar os trabalhos; extrair os dados dos trabalhos selecionados; e sintetizar os resultados dos trabalhos.

Os critérios de inclusão definidos foram os seguintes: trabalhos escritos em inglês e português, publicados como artigos completos em periódicos e anais de eventos durante o período de 2000 a 2016. Embora o início cronológico da pesquisa começar no 
ano de 2000, alguns artigos anteriores a 2000 foram incluídos devido ao grande número de citações e porque compõem a trajetória de pesquisa a respeito do tema. As palavraschaves definidas para a pesquisa nas bases bibliográficas foram as seguintes: "employee turnover"; "staff turnover"; "software development turnover"; "information system turnover" (ou "IS turnover"); "information technology turnover" (ou "IT turnover"). Essas palavras-chaves também foram utilizadas em português para a pesquisa: "rotatividade de pessoal"; "rotatividade de funcionários"; "rotatividade desenvolvimento software"; "rotatividade sistemas informação" (ou "rotatividade SI"); "rotatividade tecnologia informação" (ou "rotatividade TI").

A pesquisa foi realizada nas seguintes bases de dados bibliográficas eletrônicas: Scopus, ACM Digital Library, IEEEXPlore Digital Library e Web of Science. Após a identificação do primeiro conjunto de trabalhos (estudos primários), alguns trabalhos desse conjunto foram excluídos da revisão após a análise do título e do resumo (apesar de que em alguns casos foi necessário também analisar o texto para decidir se o trabalho era ou não relevante). Após a exclusão de trabalhos não relevantes, a pesquisa foi realizada com base nas referências contidas nos trabalhos considerados relevantes.

A avaliação da qualidade e seleção dos trabalhos foi realizada com base nos critérios definidos (citados anteriormente) e considerando os trabalhos com foco em rotatividade de pessoal, em empresa de TI / de desenvolvimento de software ou diretamente relacionados às questões de pesquisa formuladas. Ao todo foram selecionados 39 trabalhos considerados relevantes para a revisão bibliográfica. Apesar de parte dos trabalhos abordar a rotatividade em empresas de outras áreas de atuação, na avaliação da qualidade foram considerados relevantes para a revisão bibliográfica.

O objetivo da extração dos dados dos trabalhos selecionados foi obter o tipo e os detalhes da fonte e a área principal da publicação. A síntese dos resultados dos trabalhos teve por objetivo descrever a abordagem e os resultados principais, principalmente as causas/efeitos e estratégias de gestão relacionadas à rotatividade de pessoal.

Os trabalhos encontrados na literatura, em sua maioria, apresentam pesquisas relacionadas com a rotatividade com foco em gestão de pessoas (14) e gestão de TI (15). A pesquisa realizada na maior parte dos trabalhos (37) não aborda empresas brasileiras. Apenas os trabalhos de Carvalho (2012) e Ress et al. (2010) apresentam pesquisa sobre rotatividade em empresas brasileiras e somente Carvalho (2012) investigou esse tema em empresas de desenvolvimento de software. Ress et al. (2010) apresentam estudos de casos com equipes de desenvolvimento de software de empresas do segmento financeiro. O trabalho de Carvalho (2012) é uma dissertação de mestrado e, apesar de não satisfazer os critérios de inclusão, foi considerada porque está relacionada diretamente ao tema e os resultados não foram publicados em periódicos ou anais de eventos. Adicionalmente, entre os trabalhos relacionados, apenas cinco são relacionados à gestão de projeto de software em empresas de desenvolvimento de software (Rong et al. 2009; Ress et al. 2010; Carvalho 2012; Muhammad et al. 2015; Kuhrnann 2016).

A partir dos trabalhos relacionados selecionados para atender a questão de pesquisa QP1, as principais causas/efeitos e estratégias de gestão relacionadas com a rotatividade foram identificadas para as questões de pesquisa QP2 e QP3. As subseções seguintes descrevem as causas (Subseção 2.1), efeitos (Subseção 2.2) e estratégias de 
gestão (Subseção 2.3) obtidas como resultado da revisão e que foram consideradas para realizar a pesquisa de opinião.

\subsection{Causas da Rotatividade de Pessoal}

A ocorrência da rotatividade pode ser considerada multicausal e são muitas as causas discutidas na literatura. Esta pesquisa considerou as seguintes causas identificadas a partir dos trabalhos relacionados:

- Falta de comprometimento da organização (Ghosh et al. 2013; Calisir et al. 2011). O comprometimento da empresa com o funcionário é um fator importante que determina a intenção de sair da empresa.

- Insatisfação decorrente de expectativa não alcançada (Porter e Steers 1973; Ahuja et al. 2007; Ferratt et al. 2005; Zhou et al. 2016). O funcionário fica mais suscetível a sair da empresa quando percebe que as suas expectativas referentes ao trabalho não podem ser alcançadas na empresa atual.

- Falta de reconhecimento profissional (Stovel e Bontis 2002; Zhou et al. 2016). O esforço da empresa em reconhecer e expressar o valor do funcionário com bom desempenho é uma motivação para o funcionário permanecer na empresa.

- Falta de política salarial (Ghosh et al. 2013; Lim 2008; Liu 2008). O salário e o plano de carreira oferecido pela empresa são inibidores da intenção de sair da empresa.

- Ambiente de trabalho inadequado (Johnson et al. 2000; Joseph et al., 2007; Kuhrnann 2016; Chowdary et al. 2016). O ambiente de trabalho tem ligações fortes com a satisfação e o estresse do funcionário no trabalho e, consequentemente, com a sua intenção de deixar a empresa.

- Relações negativas com os colegas de trabalho (Porter e Steers 1973; Kuhrnann 2016). A socialização é a principal prática para a integração dos funcionários e o fator relacionamento pode conduzir ao estresse no trabalho que, por sua vez, influencia a decisão do funcionário de sair da empresa.

- Conflito entre trabalho e família (Ahuja et al. 2007; Calisir et al. 2011; Cai et al. 2015; Kuhrnann 2016; Zhang et al. 2016; Muhammad et al. 2015). O conflito entre trabalho e família é uma fonte de estresse no trabalho e, portanto, um fator potencial para a intenção do funcionário de sair da empresa.

- Sobrecarga de trabalho (Calisir et al. 2011; Muhammad et al. 2015). O funcionário deve receber uma quantia razoável de carga de trabalho para que não ocorra sobrecarga que, por sua vez, torna o trabalho exaustivo.

- Procura por emprego pelos colegas de trabalho (Felps et al. 2009; Porter e Steers 1973). O comportamento dos colegas de trabalho de procurar por emprego pode contagiar o funcionário a também ter a intenção de sair da empresa.

- Fatores ambientais e culturais (Wang et al. 2011; Felps et al. 2009). Os fatores ambientais (por exemplo, clima ou moradia) e culturais (por exemplo, valores, crenças e costumes regionais) influenciam a decisão do funcionário de sair da empresa. 
- Falta de treinamento periódico (Korunka et al. 2008; Stovel e Bontis, 2002). A prática de realizar treinamento periódico contribui para a melhoria da qualidade de vida no trabalho e, como consequência, para reduzir a intenção do funcionário de sair da empresa.

- Trabalho repetitivo (Thatcher et al. 2002; Chang 2010). A realização de tarefas e desafios diferentes e significativos tem efeito direto na satisfação do funcionário e, como resultado, na intenção em permanecer na empresa.

- Estilo gerencial inadequado (Longenecker e Scazzero 2003; Chiavenato 2014). O estilo gerencial de executivos, gerentes e líderes de projeto (por exemplo, muito autoritário ou muito liberal) é um fator significativo que influencia o funcionário a sair da empresa.

- Falta de comunicação na empresa (Moore 2000; Silva 2001). A comunicação direta com os funcionários, regular ou espontânea, é uma maneira efetiva de evitar muitos problemas, inclusive aqueles que contribuem para a intenção do funcionário de sair da empresa.

A causa "Falta de comunicação na empresa" não é descrita na literatura de maneira direta. No entanto, essa causa foi investigada neste trabalho porque é um fator interno à empresa considerado por Silva (2001) como um aspecto que deve ser gerenciado para um controle eficaz da rotatividade. Os livros considerados como fontes de causas da rotatividade (Chiavenato 2014; Silva 2001) não foram incluídos no total dos trabalhos relacionados porque não atendem aos critérios de inclusão previamente definidos e apenas reforçam a importância da causa relacionada.

Existem outras causas que podem influenciar a rotatividade que não foram consideradas, por exemplo, esgotamento devido ao trabalho, falta de orientação na carreira, envolvimento com o trabalho, política de gestão de pessoal, e permanência em cargos de conflito. Algumas causas são semelhantes ou especialização (caso específico) de outra causa considerada para a pesquisa enquanto outras são apenas citadas superficialmente na literatura.

\subsection{Efeitos da Rotatividade de Pessoal}

Os projetos de desenvolvimento de software são especialmente sensíveis aos efeitos da rotatividade, pois a construção do software é um trabalho intensivamente baseado em conhecimento. Os efeitos (ou consequências) da rotatividade, assim como as causas, também podem ser vários. Esses efeitos podem gerar um descontentamento nos funcionários que continuam no projeto, gerando também a intenção de sair da empresa (Calisir et al. 2011). Esta pesquisa considerou os seguintes efeitos identificados a partir dos trabalhos relacionados:

- Custo para recrutar, selecionar e contratar novos funcionários (Ang e Slaughter 2004). Para agregar um novo funcionário, a empresa tem custos diretos relacionados ao processo de recrutamento (por exemplo, divulgação da vaga e triagem de possíveis candidatos), seleção (por exemplo, conhecer com mais detalhes os candidatos e escolher aquele com o perfil mais adequado para a vaga) e contratação (por exemplo, ambientação e integração). 
- Redução de produtividade até a substituição do funcionário (Stovel e Bontis 2002; Calisir et al. 2011; Muhammad et al. 2015). A saída de um funcionário causa rompimento nos processos organizacionais da empresa e a produção somente será normalizada depois que um novo funcionário é contratado.

- Custo para treinamento de novos funcionários (Stovel e Bontis 2002; Ress et al. 2010). Ao agregar um novo funcionário, a empresa tem de investir no seu treinamento, principalmente sobre como os sistemas internos operam entre outros aspectos organizacionais.

- Atraso no cronograma do projeto (Calisir et al. 2011). A saída de um funcionário, principalmente aquele que ocupa uma posição considerada chave em um projeto, é um dos motivos que causam impacto no cronograma do projeto.

- Aumento do custo final do projeto (Johnson et al. 2000). O custo com recursos humanos (homem/hora) é o principal custo em um projeto de desenvolvimento de software e, portanto, o custo para substituir um funcionário tem impacto no custo final.

- Sobrecarga dos funcionários que continuam no projeto (Calisir et al. 2011; Chowdary et al. 2016). A saída de um funcionário da equipe de projeto sobrecarrega aqueles que continuam no projeto, pois devem assumir tarefas adicionais até que um novo funcionário seja contratado.

- Ajustes não previstos no projeto inicial (O’Connell e Kung 2007). A saída de um funcionário pode acarretar em diversos ajustes relacionados ao projeto, por exemplo, remanejamento interno de membros das equipes, redefinição de tarefas e papéis, revisão do planejamento de custos, entre outros.

- Erros cometidos por novos funcionários que afetam o projeto (Ghosh et al. 2013). A qualidade do trabalho de um novo funcionário é baixa até que esteja treinado e integrado aos processos organizacionais.

Os efeitos da rotatividade de pessoal geralmente são discutidos na literatura como consequências de causas. Os trabalhos encontrados dificilmente tratam somente dos efeitos.

\subsection{Estratégias de Gestão para Minimizar a Rotatividade de Pessoal e seus Efeitos}

A rotatividade pode ser considerada um risco real para o projeto e, se não for gerenciada, pode provocar o fracasso do projeto e prejuízo financeiro para a empresa (Rong et al. 2009; Wang et al. 2011). Portanto, o gerente de projeto deve definir uma estratégia de gestão para controlar a taxa de rotatividade com o objetivo de reduzir o risco de fracasso do projeto (Rong et al. 2009). Esta pesquisa considerou as seguintes estratégias de gestão identificadas a partir dos trabalhos relacionados:

- Adoção de política salarial e de plano de carreira (Ghosh et al. 2013; Lim 2008; Zhang et al. 2012). Um funcionário com um salário que atende as suas necessidades financeiras e também com a possibilidade de avanço na carreira apresenta mais satisfação e comprometimento no trabalho. 
- Adoção de política de benefícios e promoções por desempenho (Ang e Slaughter 2004; Cai et al. 2015). Os benefícios (por exemplo, auxílio transporte e plano de saúde) são percebidos pelo funcionário como parte da sua remuneração; as promoções (ou prêmios) por desempenho pode gerar reações psicológicas positivas desde que distribuídas de maneira justa.

- Documentação das atividades do projeto para auxiliar os novatos (Stovel e Bontis 2002). A documentação clara dos processos pelos quais o desenvolvimento do projeto passa é uma forma de gestão de conhecimento que beneficia não somente os novos funcionários contratados em substituição dos que saíram da empresa, mas também todos os envolvidos no projeto.

- Realização de treinamentos periódicos em novas tecnologias (Stovel e Bontis 2002). A oferta de oportunidades de treinamento é uma prática que pode proporcionar a melhoria no desempenho do funcionário (qualidade $\mathrm{e}$ produtividade) e na qualidade de vida no trabalho, contribuindo para o aumento da motivação e satisfação no trabalho e influenciando o comportamento e atitude com relação à intenção de sair da empresa.

- Realização de atividades em pares para minimizar a saída de funcionário (Carvalho 2012). A realização de atividades em pares reduz o impacto da saída de um funcionário porque promove o compartilhamento do conhecimento e aumenta a facilidade de manutenção.

- Alternância de papéis para o funcionário exercer mais de uma função (Ress et al. 2010). A divisão e alternância dos papéis executados entre os integrantes da equipe do projeto reduz o impacto da saída de um funcionário porque contribui para a flexibilidade de seus funcionários em assumir as funções de seus colegas.

- Uso de entrevistas para avaliar o risco antes da contratação (O'Connell e Kung 2007; Ghosh et al. 2013). Alguns candidatos possuem alta propensão em trocar de empresa e essa característica pode ser identificada ainda durante o processo de recrutamento e seleção.

- Realização de treinamentos no início da contratação (Stovel e Bontis 2002; Muhammad et al. 2015). O treinamento inicial prepara o novo funcionário para assumir a função para a qual foi contratado, promove uma oportunidade de socialização e fornece informações sobre aspectos importantes da cultura organizacional, contribuindo para o aumento da motivação e satisfação no novo trabalho que influencia a intenção de permanecer na empresa.

\section{Metodologia da Pesquisa}

$\mathrm{O}$ método utilizado nesta pesquisa foi a pesquisa de opinião (survey), que tem a finalidade principal de identificar os fatores que caracterizam ou que podem justificar um determinado evento em uma população ou amostra. Uma pesquisa de opinião é conduzida por meio do uso de instrumentos que permitem medir ou descrever o problema investigado (Kaptein et al. 2010). A técnica de questionário foi utilizada para a coleta de dados.

A pesquisa de opinião foi delineada para responder às seguintes Questões de Pesquisa $(\mathrm{QP})$ relacionadas com a rotatividade de pessoal: 
- QP1: Quais as principais causas e efeitos da rotatividade de pessoal segundo a opinião de profissionais de empresas brasileiras de desenvolvimento de software?

- QP2: Quais as principais estratégias de gestão para minimizar a rotatividade de pessoal e seus efeitos segundo a opinião de profissionais de empresas brasileiras de desenvolvimento de software?

O objetivo subjacente é verificar se é possível estabelecer uma relação de ordem no sentido de identificar quais os profissionais mais concordam que sejam causas/efeitos da rotatividade de pessoal ou que sejam estratégias de gestão para minimizar a rotatividade de pessoal e seus efeitos.

A pesquisa de opinião foi realizada em cinco etapas: (1) elaboração do instrumento de coleta de dados (questionário); (2) pré-teste do questionário; (3) seleção da amostra; (4) aplicação do questionário; e (5) análise e interpretação dos dados. $\mathrm{O}$ questionário foi elaborado com questões em escala Likert de cinco pontos e questões de múltipla escolha. O questionário foi dividido nas seguintes seções: caracterização do respondente e da sua empresa atual, com 12 questões de múltipla escolha (algumas opções com faixa de valores); concordância com declarações sobre rotatividade, com 14 questões em escala Likert; principais causas e efeitos, com 02 questões de múltipla escolha (resposta múltipla); estratégias de gestão empregadas, com 08 questões em escala Likert e 01 questão de múltipla escolha (resposta múltipla).

No pré-teste realizado, o questionário foi aplicado a 15 respondentes de uma empresa que foi parte da amostra. De 10 a 20 respondentes são suficientes para validar o instrumento independentemente do tamanho da amostra (Grossman et al. 2009). O préteste é considerado um estudo piloto conduzido antes da aplicação do questionário. $\mathrm{O}$ principal objetivo do pré-teste é fornecer subsídios para melhorar a versão final do questionário (Petrillo et al. 2011). Os resultados do pré-teste foram utilizados para simular a análise e interpretação dos dados. O respondente do pré-teste também pôde fornecer uma opinião por meio de uma questão aberta sobre a qualidade das questões e sugerir alguma melhoria. As opiniões dos respondentes a respeito das questões foram positivas, qualificando o instrumento para a próxima etapa. Houve 19 comentários e nenhum deles informou qualquer dificuldade em responder as questões.

O questionário foi enviado aos profissionais de 40 empresas brasileiras de desenvolvimento de software. A amostra de profissionais foi determinada usando o critério de amostragem não probabilística por conveniência, também conhecida por amostragem não intencional (Slyngstad et al. 2006). A mensagem para os respondentes incluiu um link para a página do questionário online que esteve disponível por 20 dias e recebeu 67 respostas. Os dados foram formatados em uma planilha e importados para uma ferramenta estatística para facilitar a análise. A análise foi realizada por meio de estatística descritiva e inferencial. O teste estatístico de Wilcoxon pareado (Wilcoxon signed-rank test) foi utilizado para o teste de hipóteses porque é adequado para a análise de dados que são medidos em uma escala ordinal (por exemplo, escala Likert), e indicado para o caso em que as amostras são dependentes (por exemplo, quando duas medidas são tomadas de uma mesma amostra). 


\section{Resultados e Discussão}

Nesta seção, os resultados da análise dos dados obtidos a partir do questionário são apresentados e discutidos. Inicialmente, a caracterização dos respondentes e das empresas dos respondentes é apresentada (Subseção 4.1) para ressaltar a relevância da amostra obtida para o contexto desta pesquisa. Na sequência são apresentados os resultados relacionados às causas e efeitos da rotatividade (Subseção 4.2) e relacionados às estratégias de gestão (Subseção 4.3). Ao final, são realizadas algumas comparações entre partes diferentes da amostra (Subseção 4.4).

\subsection{Caracterização dos Respondentes}

Com relação aos respondentes, todos são profissionais que trabalham em projetos de desenvolvimento de software e $46,3 \%$ possuem de um a três anos de trabalho na empresa atual (26,9\% possuem mais de cinco anos, 10,4 possuem de três a cinco anos e apenas $16,4 \%$ possuem menos de um ano). Além disso, $59,7 \%$ atuaram em três ou mais empresas e $82,1 \%$ atuaram em mais de uma empresa (percentual que inclui três ou mais empresas). Entre os respondentes, $83,6 \%$ são homens, $80,6 \%$ possuem entre 21 e 40 anos (3,0\% com menos de 21 anos e $16,4 \%$ com mais de 40 anos), $49,3 \%$ são casados e $46,3 \%$ solteiros, $67,2 \%$ não têm filhos. Os respondentes têm formação de tecnólogo (50,8\%), computação $(17,9 \%)$, análise de sistemas $(16,4 \%)$ e outras formações na área $(14,9 \%)$.

Com relação à atuação dos respondentes nas empresas, $64,2 \%$ ocupam cargos de analista de sistemas ou programador, $26,9 \%$ são diretores, gerentes ou supervisores e $8,9 \%$ ocupam outras posições. Quase metade dos respondentes $(47,77 \%)$ atuou em mais de um papel na empresa. Em geral, um papel corresponde a uma responsabilidade que uma pessoa possui dentro de um projeto, sendo que uma mesma pessoa pode assumir um ou mais papéis em um mesmo projeto.

Quanto ao número de funcionários das empresas dos respondentes, 62,9 possuem de um a 50 funcionários (com 43,3\% dessas empresas com mais de 15 funcionários), $11,3 \%$ entre 51 e 500 funcionários e $25,4 \%$ possuem mais de mil funcionários. Parte significativa das empresas dos respondentes utiliza processo de desenvolvimento de software bem definido $(73,1 \%)$, utilizam práticas ágeis pelo menos parcialmente $(64,2 \%)$ e possuem certificação de melhoria de processo de software $(68,7 \%)$.

Os resultados indicam que os respondentes têm experiência profissional na área de desenvolvimento de software e que a maioria deixou a sua empresa anterior por algum motivo, isto é, estes respondentes possuem a experiência de ter vivenciado a rotatividade de pessoal sob algum aspecto. Além disso, os respondentes são profissionais de 40 empresas diferentes. Portanto, sob esses aspectos, a amostra de profissionais de empresas brasileiras de desenvolvimento de software pode ser considerada representativa para esta pesquisa.

\subsection{Causas e Efeitos da Rotatividade de Pessoal}

Os respondentes expressaram o seu nível de concordância a respeito das causas por meio de questões em escala Likert de cinco pontos (1: discordo totalmente; 2: discordo; 3: neutro; 4: concordo; 5: concordo totalmente). O resultado é apresentado na Tabela 1, 
que apresenta uma classificação pela mediana (Med.) e depois pela média para diferenciar os resultados com medianas iguais. As quatro primeiras causas são as que possuem maior concordância, considerando que a maioria dos respondentes expressou concordo ou concordo totalmente $(91 \%, 82 \%, 90 \%$ e $89 \%$ dos respondentes, respectivamente para as causas $1,2,3$ e 4$)$.

Uma análise estatística inferencial foi realizada para testar se a classificação (ordem) da Tabela 1 é significativa estatisticamente (isto é, se a mediana de uma causa pode ser considerada maior que a mediana de todas as causas classificadas abaixo desta na tabela). Assim, as hipóteses com relação à mediana das respostas foram definidas a partir da classificação da Tabela 1. Por exemplo, a hipótese de que a causa falta de reconhecimento profissional, classificada em primeiro, tem a mediana maior que a causa falta de política salarial, classificada em segundo. Dessa maneira, foram definidas as demais hipóteses para testar se a causa falta de reconhecimento profissional tem a mediana maior que a terceira, quarta, quinta causa e assim por diante. Depois, foram definidas as hipóteses para testar se a causa falta de política salarial, classificada em segundo, tem a mediana maior que as demais causas abaixo na tabela e assim sucessivamente para todas as causas. Os resultados de p-valor obtidos a partir dos testes de hipóteses realizados por meio do teste estatístico de Wilcoxon pareado com intervalo de confiança de 95\% são apresentados na Tabela 2.

$\mathrm{Na}$ Tabela 2, os resultados com p-valor $<0,05$ indicam que existe diferença estatística significativa, isto é, existe indicações estatísticas de que a causa indicada na coluna respectiva ao p-valor tem mediana maior que a causa indicada na linha correspondente. Por exemplo, existe diferença estatística significativa de que a causa falta de reconhecimento profissional (coluna 1) tem mediana maior que a causa estilo gerencial inadequado (linha 5), uma vez que p-valor $=0,0462<0,05$. A mesma afirmação não seria válida para a causa insatisfação decorrente de expectativa não alcançada (linha 4), uma vez que p-valor $=0,2621>0,05$.

Os resultados da Tabela 2 indicam que as quatro primeiras causas estão ao menos entre as seis primeiras da classificação, conforme os resultados do p-valor $<0,05$ das colunas 1 a 4 a partir da linha 7 (relações negativas com os colegas de trabalho) até a última linha (fatores ambientais e culturais). No entanto, não existe diferença estatística significativa para fazer inferência sobre as causas estilo gerencial inadequado e ambiente de trabalho inadequado, conforme os resultados do p-valor $>0,05$ da linha 5 (colunas 2, 3 e 4) e da linha 6 (coluna 2). 
Tabela 1. Resultado das questões em escala Likert sobre as causas da rotatividade de pessoal

\begin{tabular}{|c|c|c|c|c|c|c|c|c|c|}
\hline & $\begin{array}{c}\text { Causas da rotatividade } \\
\text { de pessoal }\end{array}$ & $1(\%)$ & $2(\%)$ & $3(\%)$ & $4(\%)$ & $5(\%)$ & Med. & Média & Moda \\
\hline 1 & $\begin{array}{l}\text { Falta de reconhecimento } \\
\text { profissional }\end{array}$ & 0,00 & 0,00 & 8,96 & 38,81 & 52,23 & 5 & 4,433 & 5 \\
\hline 2 & Falta de política salarial & 1,49 & 2,99 & 13,43 & 29,85 & 52,24 & 5 & 4,284 & 5 \\
\hline 3 & $\begin{array}{l}\text { Falta de comprometimento da } \\
\text { organização }\end{array}$ & 1,49 & 0,00 & 8,96 & 38,81 & 50,74 & 4 & 4,343 & 5 \\
\hline 4 & $\begin{array}{l}\text { Insatisfação decorrente de } \\
\text { expectativa não alcançada }\end{array}$ & 1,49 & 1,49 & 7,46 & 40,30 & 49,26 & 4 & 4,313 & 5 \\
\hline 5 & Estilo gerencial inadequado & 2,99 & 7,46 & 11,94 & 38,81 & 38,80 & 4 & 4,090 & 5 \\
\hline 6 & $\begin{array}{l}\text { Ambiente de trabalho } \\
\text { inadequado }\end{array}$ & 4,48 & 4,48 & 13,43 & 38,81 & 38,80 & 4 & 4,000 & 4 \\
\hline 7 & $\begin{array}{l}\text { Relações negativas com os } \\
\text { colegas de trabalho }\end{array}$ & 4,48 & 5,97 & 20,90 & 32,84 & 35,81 & 4 & 3,955 & 5 \\
\hline 8 & $\begin{array}{l}\text { Conflito entre trabalho e } \\
\text { família }\end{array}$ & 4,48 & 7,46 & 22,39 & 34,33 & 31,34 & 4 & 3,821 & 4 \\
\hline 9 & Trabalho repetitivo & 5,97 & 7,46 & 23,88 & 32,84 & 29,85 & 4 & 3,761 & 4 \\
\hline 10 & Sobrecarga de trabalho & 5,97 & 5,97 & 28,36 & 37,31 & 22,39 & 4 & 3,612 & 4 \\
\hline 11 & $\begin{array}{l}\text { Falta de comunicação na } \\
\text { empresa }\end{array}$ & 2,99 & 14,93 & 19,40 & 44,78 & 17,90 & 4 & 3,582 & 4 \\
\hline 12 & Falta de treinamento periódico & 4,48 & 19,40 & 25,37 & 38,81 & 11,94 & 3 & 3,269 & 3 \\
\hline 13 & $\begin{array}{l}\text { Procura por emprego pelos } \\
\text { colegas de trabalho }\end{array}$ & 16,42 & 14,93 & 28,36 & 29,85 & 10,44 & 3 & 3,000 & 3 \\
\hline 14 & Fatores ambientais e culturais & 17,91 & 19,40 & 38,81 & 16,42 & 7,46 & 3 & 2,701 & 3 \\
\hline
\end{tabular}


Tabela 2. Resultado (p-valor) do teste de Wilcoxon pareado para as hipóteses relacionadas à ordem das medianas das questões sobre as causas da rotatividade de pessoal

\begin{tabular}{|c|c|c|c|c|c|c|c|c|c|c|c|c|c|c|c|c|}
\hline & & & 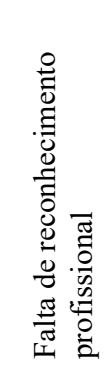 & 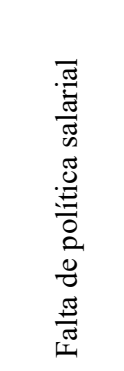 & 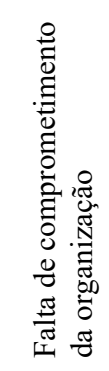 & 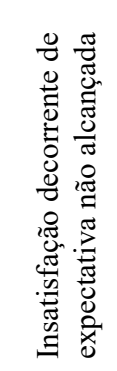 & 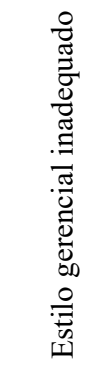 & 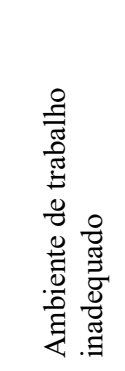 & 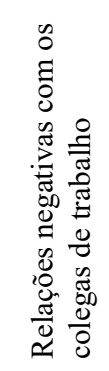 & 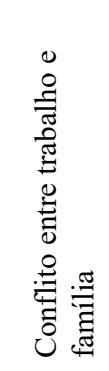 & 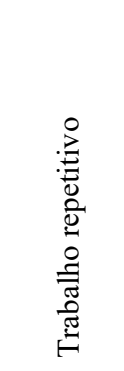 & 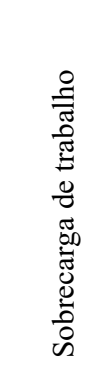 & 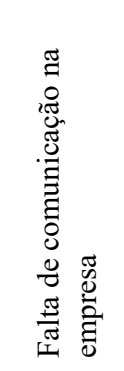 & 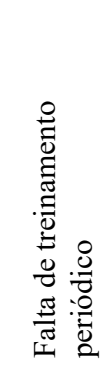 & 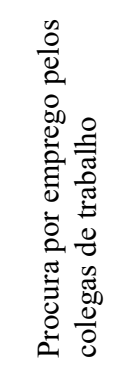 & 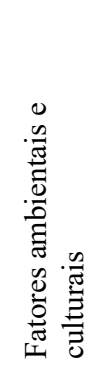 \\
\hline & & & 1 & 2 & 3 & 4 & 5 & 6 & 7 & 8 & 9 & 10 & 11 & 12 & 13 & 14 \\
\hline & & Mediana & 5 & 5 & 4 & 4 & 4 & 4 & 4 & 4 & 4 & 4 & 4 & 3 & 3 & 3 \\
\hline Falta de reconhecimento profissional & 1 & 5 & - & & & & & & & & & & & & & \\
\hline Falta de política salarial & 2 & 5 & 0,0944 & & & & & & & & & & & & & \\
\hline Falta de comprometimento da organização & 3 & 4 & 0,2759 & 0,6581 & & & & & & & & & & & & \\
\hline $\begin{array}{l}\text { Insatisfação decorrente de expectativa não } \\
\text { alcançada }\end{array}$ & 4 & 4 & 0,2101 & 0,6121 & 0,4570 & & & & & & & & & & & \\
\hline Estilo gerencial inadequado & 5 & 4 & 0,0253 & 0,1717 & 0,0819 & 0,0778 & & & & & & & & & & \\
\hline Ambiente de trabalho inadequado & 6 & 4 & 0,0075 & 0,0630 & 0,0161 & 0,0161 & 0,2648 & & & & & & & & & \\
\hline Relações negativas com os colegas de trabalho & 7 & 4 & 0,0024 & 0,0358 & 0,0236 & 0,0236 & 0,1738 & 0,3493 & & & & & & & & \\
\hline Conflito entre trabalho e família & 8 & 4 & 0,0002 & 0,0055 & 0,0008 & 0,0019 & 0,0581 & 0,1508 & 0,2376 & & & & & & & \\
\hline Trabalho repetitivo & 9 & 4 & 0,0002 & 0,0050 & 0,0013 & 0,0004 & 0,0234 & 0,0894 & 0,1200 & 0,4013 & & & & & & \\
\hline Sobrecarga de trabalho & 10 & 4 & 0,0000 & 0,0000 & 0,0000 & 0,0000 & 0,0039 & 0,0054 & 0,0232 & 0,1934 & 0,1822 & & & & & \\
\hline Falta de comunicação na empresa & 11 & 4 & 0,0000 & 0,0000 & 0,0000 & 0,0000 & 0,0015 & 0,0049 & 0,0148 & 0,1021 & 0,1760 & 0,4727 & & & & \\
\hline Falta de treinamento periódico & 12 & 3 & 0,0000 & 0,0000 & 0,0000 & 0,0000 & 0,0000 & 0,0000 & 0,0002 & 0,0012 & 0,0077 & 0,0252 & 0,0388 & & & \\
\hline Procura por emprego pelos colegas de trabalho & 13 & 3 & 0,0000 & 0,0000 & 0,0000 & 0,0000 & 0,0000 & 0,0000 & 0,0000 & 0,0000 & 0,0000 & 0,0044 & 0,0021 & 0,0950 & & \\
\hline Fatores ambientais e culturais & 14 & 3 & 0,0000 & 0,0000 & 0,0000 & 0,0000 & 0,0000 & 0,0000 & 0,0000 & 0,0000 & 0,0000 & 0,0000 & 0,0000 & 0,0000 & 0,1018 & - \\
\hline
\end{tabular}


Os respondentes também selecionaram as cinco principais causas por meio de uma questão de múltipla escolha (resposta múltipla). Nessa questão, as mesmas causas investigadas nas questões em escala Likert foram utilizadas com a finalidade de fortalecer os resultados e realizar comparações. O resultado dessa questão de múltipla escolha é mostrado na Tabela 3. A coluna "Frequência" indica o número e porcentagem de respondentes que selecionaram a opção correspondente. Ao fazer essa seleção, cada respondente pôde ponderar melhor e escolher as principais causas em relação às demais. Um resultado que poderia ser considerado normal (ou esperado) seria a falta de política salarial como a causa mais selecionada. Entretanto, a insatisfação decorrente de expectativa não alcançada, o estilo gerencial inadequado (por exemplo, muito autoritário ou muito liberal) e a falta de reconhecimento profissional foram causas mais selecionadas do que a falta de política salarial.

Comparando esses resultados (Tabela 3) com os apresentados na literatura, a falta de comprometimento da organização, citada por Ghosh et al. (2013) e Calisir et al. (2011) como uma das principais causas da rotatividade, não foi uma das causas mais selecionadas $(31 \%$ dos respondentes selecionaram essa opção). A falta de reconhecimento profissional (Zhou et al. 2016; Stovel e Bontis 2002) e a falta de política salarial (Ghosh et al. 2013; Lim 2008) estão entre as mais selecionadas pelos respondentes. Semelhante ao apresentado na literatura (Zhou et al. 2016; Ahuja et al. 2007; Ferrat et al. 2005; Porter e Steers 1973), a insatisfação decorrente de expectativa não alcançada na empresa também foi considerada uma das principais causas $(60 \%$ dos respondentes selecionaram essa opção). Felps et al. (2009) concluiu que a procura por emprego pelos colegas de trabalho influencia a decisão do funcionário de deixar a empresa, mas somente 3\% dos respondentes selecionaram essa opção como uma das principais causas.

Tabela 3. Resultado da questão de múltipla escolha sobre as causas da rotatividade de pessoal

\begin{tabular}{clcc}
\hline \multicolumn{1}{c}{ Causas da Rotatividade de Pessoal } & Frequência \\
\hline 1 & Insatisfação decorrente de expectativa não alcançada & 62 & $60 \%$ \\
$2-3$ & Estilo gerencial inadequado & 41 & $59 \%$ \\
$2-3$ & Falta de reconhecimento profissional & 41 & $59 \%$ \\
4 & Falta de política salarial & 29 & $41 \%$ \\
5 & Relações negativas com os colegas de trabalho & 28 & $40 \%$ \\
6 & Trabalho repetitivo & 24 & $34 \%$ \\
$7-8$ & Sobrecarga de trabalho & 22 & $31 \%$ \\
$7-8$ & Falta de comprometimento da organização & 22 & $31 \%$ \\
9 & Ambiente de trabalho inadequado & 19 & $27 \%$ \\
10 & Falta de comunicação na empresa & $13 \%$ \\
11 & Conflito entre trabalho e família & 12 & $17 \%$ \\
12 & Falta de treinamento periódico & 11 & $16 \%$ \\
$13-14$ & Procura por emprego pelos colegas de trabalho & 02 & $03 \%$ \\
$13-14$ & Fatores ambientais e culturais & 02 & $03 \%$ \\
\hline
\end{tabular}


Os respondentes também selecionaram os cinco principais efeitos da rotatividade em uma questão de múltipla escolha (resposta múltipla). O resultado dessa questão de múltipla escolha é apresentado na Tabela 4. Comparando esses resultados com a literatura, assim como apresentado por Chowdary et al. (2016) e Calisir et al. (2011), a sobrecarga dos funcionários que continuam no projeto, a redução de produtividade até a substituição do funcionário e os atrasos no cronograma do projeto também foram considerados pelos respondentes desta pesquisa como parte dos principais efeitos. Muhammad et al. (2015) e também Stovel e Bontis (2002) descreveram a redução de produtividade até a substituição do funcionário como um dos efeitos da rotatividade.

Tabela 4. Resultado da questão de múltipla escolha sobre os efeitos da rotatividade de pessoal

\begin{tabular}{llcc}
\hline & \multicolumn{1}{c}{ Efeitos da Rotatividade de Pessoal } & \multicolumn{2}{c}{ Frequência } \\
\hline 1 & Sobrecarga dos funcionários que continuam no projeto & 64 & $91 \%$ \\
2 & Redução de produtividade até a substituição do funcionário & 51 & $73 \%$ \\
3 & Atrasos no cronograma do projeto & 50 & $71 \%$ \\
4 & Investimento de tempo e recursos para treinamento de novos funcionários & 47 & $67 \%$ \\
5 & Custo para recrutar e contratar novos funcionários & 38 & $54 \%$ \\
6 & Ajustes não previstos no projeto inicial & 34 & $49 \%$ \\
7 & Erros cometidos por novos funcionários que afetam o projeto & 31 & $44 \%$ \\
8 & Aumento do custo final do projeto & 26 & $37 \%$ \\
9 & Outros & 4 & $6 \%$ \\
\hline
\end{tabular}

\subsection{Estratégias de Gestão para Minimizar a Rotatividade de Pessoal e seus Efeitos}

Os respondentes expressaram o seu nível de concordância a respeito de estratégias de gestão por meio de questões em escala Likert de cinco pontos. Na Tabela 5 é possível observar o nível de concordância ou discordância obtido a partir das respostas para cada estratégia de gestão. As quatro primeiras foram as de maior concordância, considerando que a maioria dos respondentes expressou concordo ou concordo totalmente $(91 \%, 89 \%$, $75 \%$ e $70 \%$ dos respondentes, respectivamente para as estratégias 1, 2, 3 e 4).

Uma análise estatística inferencial foi realizada de maneira similar à descrita anteriormente (para as causas da rotatividade). Os resultados dos testes de hipótese realizados por meio do teste de Wilcoxon pareado com intervalo de confiança de $95 \%$ são apresentados na Tabela 6. Os resultados com p-valor $<0,05$ indicam que existe diferença estatística significativa. 
Tabela 5. Resultado das questões em escala Likert sobre as estratégias de gestão para minimizar a rotatividade de pessoal e seus efeitos

\begin{tabular}{|c|c|c|c|c|c|c|c|c|c|}
\hline & Estratégias de Gestão & $1(\%)$ & $2(\%)$ & $3(\%)$ & $4(\%)$ & $5(\%)$ & Med. & Média & Moda \\
\hline 1 & $\begin{array}{l}\text { Adoção de política salarial e de } \\
\text { plano de carreira }\end{array}$ & 1,49 & 0,00 & 7,46 & 25,37 & 65,68 & 5 & 4,508 & 5 \\
\hline 2 & $\begin{array}{l}\text { Adoção de política de benefícios } \\
\text { e promoções por desempenho }\end{array}$ & 1,49 & 2,99 & 5,97 & 28,36 & 61,19 & 5 & 4,448 & 5 \\
\hline 3 & $\begin{array}{l}\text { Documentação das atividades do } \\
\text { projeto para auxiliar os novatos }\end{array}$ & 2,99 & 7,46 & 14,93 & 26,87 & 47,75 & 4 & 4,060 & 5 \\
\hline 4 & $\begin{array}{l}\text { Realização de treinamentos } \\
\text { periódicos }\end{array}$ & 7,46 & 7,46 & 14,93 & 37,31 & 32,84 & 4 & 3,716 & 4 \\
\hline 5 & $\begin{array}{l}\text { Realização de atividades em } \\
\text { pares para minimizar a saída de } \\
\text { funcionário }\end{array}$ & 5,97 & 5,97 & 37,31 & 28,36 & 22,39 & 4 & 3,582 & 3 \\
\hline 6 & $\begin{array}{l}\text { A alternância de papéis para o } \\
\text { funcionário exercer mais de uma } \\
\text { função }\end{array}$ & 5,97 & 13,43 & 26,87 & 32,84 & 20,89 & 4 & 3,418 & 4 \\
\hline 7 & $\begin{array}{l}\text { O Uso de entrevistas para avaliar } \\
\text { o risco antes da contratação }\end{array}$ & 4,48 & 13,43 & 32,84 & 29,85 & 19,40 & 3 & 3,388 & 3 \\
\hline 8 & $\begin{array}{l}\text { A realização de treinamentos no } \\
\text { início da contratação. }\end{array}$ & 10,45 & 10,45 & 29,85 & 32,84 & 16,41 & 3 & 3,254 & 4 \\
\hline
\end{tabular}

Nos sete testes de hipótese em que a estratégia de gestão adoção de política salarial e de plano de carreira foi analisada, seis dos resultados de p-valor apoiam a hipótese de que existe diferença estatística (coluna 1). De maneira similar, a adoção de política de benefícios e promoções por desempenho e a documentação das atividades do projeto para auxiliar os novatos também apresentaram resultados estatísticos significativos com relação às demais estratégias (colunas 2 e 3). Portanto, os resultados fornecem indicações estatísticas de que as três primeiras têm mediana maior do que as demais estratégias.

Comparando esses resultados (Tabela 6) com os apresentados na literatura, Ghosh et al. (2013), Zhang et al. (2012) e Lim (2008) também apresentaram a adoção de política salarial e de plano de carreira como uma estratégia de gestão para minimizar a rotatividade. Ang e Slaughter (2004), ao analisar o impacto de estratégias de recursos humanos sobre a rotatividade, consideraram a adoção de política de benefícios e promoções por desempenho para este contexto. Os resultados obtidos por Stovel e Bontis (2002) sugerem o aumento da gestão do conhecimento (por exemplo, por meio da documentação das atividades do projeto) como estratégia para minimizar os efeitos da rotatividade. 
Tabela 6. Resultado (p-valor) do teste de Wilcoxon pareado para as hipóteses relacionadas à ordem das medianas das questões sobre as estratégias de gestão para minimizar a rotatividade de pessoal e seus efeitos

\begin{tabular}{|c|c|c|c|c|c|c|c|c|c|c|}
\hline & & & 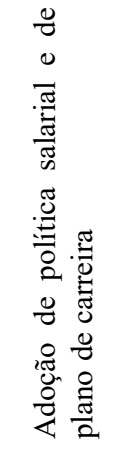 & 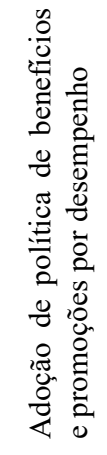 & 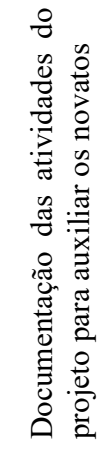 & 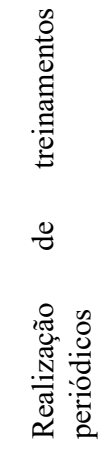 & 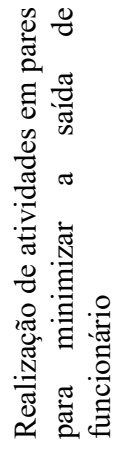 & 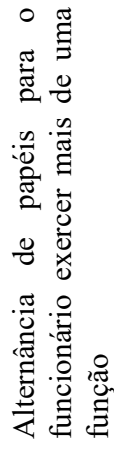 & 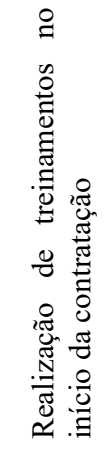 & 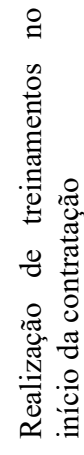 \\
\hline & & & 1 & 2 & 3 & 4 & 5 & 6 & 7 & 8 \\
\hline & & Med. & 5 & 5 & 4 & 4 & 4 & 4 & 3 & 3 \\
\hline $\begin{array}{l}\text { Adoção de política salarial e } \\
\text { de plano de carreira }\end{array}$ & 1 & 5 & - & & & & & & & \\
\hline $\begin{array}{l}\text { Adoção de benefícios e } \\
\text { promoções }\end{array}$ & 2 & 5 & 0,3861 & & & & & & & \\
\hline $\begin{array}{l}\text { Documentação das atividades } \\
\text { do projeto para auxiliar os } \\
\text { novatos }\end{array}$ & 3 & 4 & 0,0011 & 0,0140 & & & & & & \\
\hline $\begin{array}{lrr}\text { Realização } & \text { de } & \text { treinamentos } \\
\text { periódicos } & \text { em } & \text { novas } \\
\text { tecnologias } & & \\
\end{array}$ & 4 & 4 & 0,0000 & 0,0000 & 0,0294 & & & & & \\
\hline $\begin{array}{l}\text { Realização de atividades em } \\
\text { pares para minimizar a saída } \\
\text { de funcionário }\end{array}$ & 5 & 4 & 0,0000 & 0,0000 & 0,0018 & 0,1871 & & & & \\
\hline $\begin{array}{l}\text { Alternância de papéis para o } \\
\text { funcionário exercer mais de } \\
\text { uma função }\end{array}$ & 6 & 4 & 0,0000 & 0,0000 & 0,0009 & 0,0230 & 0,1509 & & & \\
\hline $\begin{array}{l}\text { Uso de entrevistas para avaliar } \\
\text { o risco antes da contratação }\end{array}$ & 7 & 3 & 0,0000 & 0,0000 & 0,0004 & 0,0233 & 0,1562 & 0,3639 & & \\
\hline $\begin{array}{l}\text { Realização de treinamentos no } \\
\text { início da contratação }\end{array}$ & 8 & 3 & 0,0000 & 0,0000 & 0,0000 & 0,0013 & 0,0779 & 0,1077 & 0,2257 & - \\
\hline
\end{tabular}

\subsection{Comparações entre Partes Diferentes da Amostra}

Os dados também foram analisados de acordo com partes diferentes da amostra. Nessa comparação, a análise teve abordagem exploratória, uma vez que não é possível obter resultados significativos por meio de análise estatística inferencial devido ao tamanho das partes da amostra. No entanto, os resultados da análise estatística descritiva servem como sugestões para novas investigações.

A amostra foi dividida nos seguintes grupos de respondentes: com e sem cargo gerencial (20 e 47 respondentes, respectivamente); de empresas com menos e mais de 50 funcionários (42 e 25 respondentes), para considerar uma divisão entre pequenas/médias empresas e grandes empresas; de empresas com processo de desenvolvimento de software definido e com processo parcialmente definido (49 e 14 
respondentes); de empresas com e sem certificação de melhoria de processo de software (16 e 46 respondentes). Como apenas quatro respondentes atuam em empresas sem processo de desenvolvimento de software, esses dados não foram considerados para as partes da amostra. Cinco dos respondentes não souberam opinar a respeito da existência ou não de certificação de melhoria de processo de software na empresa e também não foram considerados.

Na Tabela 7 são apresentados os resultados da comparação para as causas da rotatividade. O número nas colunas "Cargo gerencial", "Número de funcionários", "Processo de software definido" e "Certificação de melhoria de processo" indica a posição na classificação da parte da amostra correspondente para comparação com a classificação original na coluna "Causas da rotatividade de pessoal" (proveniente da Tabela 1).

Tabela 7. Resultado da comparação entre partes da amostra para as causas da rotatividade de pessoal

\begin{tabular}{|c|c|c|c|c|c|c|c|c|c|}
\hline \multicolumn{2}{|c|}{ Causas da rotatividade de pessoal } & \multicolumn{2}{|c|}{$\begin{array}{c}\text { Cargo } \\
\text { gerencial }\end{array}$} & \multicolumn{2}{|c|}{$\begin{array}{l}\text { Número de } \\
\text { funcionários }\end{array}$} & \multicolumn{2}{|c|}{$\begin{array}{c}\text { Processo de } \\
\text { software } \\
\text { definido }\end{array}$} & \multicolumn{2}{|c|}{$\begin{array}{l}\text { Certificação de } \\
\text { melhoria de } \\
\text { processo }\end{array}$} \\
\hline & & Com & Sem & $<\mathbf{5 0}$ & $>\mathbf{5 0}$ & Sim & Parcial & Com & Sem \\
\hline 1 & $\begin{array}{l}\text { Falta de reconhecimento } \\
\text { profissional }\end{array}$ & 2 & 1 & 3 & 1 & 1 & 2 & 1 & 1 \\
\hline 2 & Falta de política salarial & 4 & 3 & 1 & 4 & 4 & 1 & 2 & 4 \\
\hline 3 & $\begin{array}{l}\text { Falta de comprometimento da } \\
\text { organização }\end{array}$ & 1 & 4 & 2 & 3 & 3 & 3 & 3 & 3 \\
\hline 4 & $\begin{array}{l}\text { Insatisfação decorrente de } \\
\text { expectativa não alcançada }\end{array}$ & 3 & 2 & 4 & 5 & 2 & 4 & 4 & 2 \\
\hline 5 & Estilo gerencial inadequado & 5 & 5 & 6 & 2 & 5 & 8 & 5 & 5 \\
\hline 6 & $\begin{array}{l}\text { Ambiente de trabalho } \\
\text { inadequado }\end{array}$ & 6 & 7 & 5 & 7 & 6 & 6 & 6 & 6 \\
\hline 7 & $\begin{array}{l}\text { Relações negativas com os } \\
\text { colegas de trabalho }\end{array}$ & 9 & 6 & 7 & 6 & 7 & 5 & 7 & 7 \\
\hline 8 & $\begin{array}{l}\text { Conflito entre trabalho e } \\
\text { família }\end{array}$ & 8 & 8 & 8 & 11 & 8 & 9 & 8 & 9 \\
\hline 9 & Trabalho repetitivo & 7 & 9 & 9 & 8 & 9 & 7 & 9 & 8 \\
\hline 10 & Sobrecarga de trabalho & 11 & 10 & 10 & 10 & 10 & 10 & 10 & 10 \\
\hline 11 & $\begin{array}{l}\text { Falta de comunicação na } \\
\text { empresa }\end{array}$ & 10 & 11 & 11 & 9 & 11 & 11 & 11 & 11 \\
\hline 12 & Falta de treinamento periódico & 12 & 12 & 12 & 12 & 12 & 13 & 12 & 12 \\
\hline 13 & $\begin{array}{l}\text { Procura por emprego pelos } \\
\text { colegas de trabalho }\end{array}$ & 13 & 13 & 13 & 13 & 13 & 12 & 13 & 13 \\
\hline 14 & Fatores ambientais e culturais & 14 & 14 & 14 & 14 & 14 & 14 & 14 & 14 \\
\hline
\end{tabular}

Nos resultados dos respondentes com ou sem cargo gerencial, as quatro primeiras causas são as com maior nível de concordância. Em especial, os respondentes com cargo gerencial ( 20 respondentes) concordam mais que a falta de comprometimento da organização é uma causa da rotatividade. Para os respondentes sem cargo gerencial (47 respondentes) a causa com maior nível de concordância é a falta de reconhecimento profissional. 
Os respondentes de empresas com mais de 50 funcionários (25 respondentes) concordam mais com o estilo gerencial inadequado como causa da rotatividade. Em comparação com a literatura, Chiavenato (2010) faz referência ao estilo gerencial como um dos fatores internos à empresa que é responsável por uma alta taxa de rotatividade.

Os resultados da comparação entre respondentes de empresas com processo de desenvolvimento de software definido e com processo parcialmente definido e entre respondentes de empresas com e sem certificação de melhoria de processo de desenvolvimento de software não apresentaram muita divergência de opinião com relação às quatro primeiras causas. No entanto, os respondentes de empresas com processo parcialmente definido (14 respondentes) concordam mais que a falta de política salarial é uma causa da rotatividade. Ghosh et al. (2013), Lim (2008) e Zhang et al. (2012) fazem referência à política salarial como sendo um dos fatores internos que geram a rotatividade na empresa.

$\mathrm{Na}$ Tabela 8 são apresentados os resultados da comparação para as estratégias de gestão. As três primeiras estratégias da classificação original (Tabela 1) são as com maior nível de concordância entre os respondentes das partes da amostra. Apenas os respondentes de empresa com processo definido consideram mais a realização de treinamentos periódicos em novas tecnologias.

Tabela 8. Resultado da comparação entre partes da amostra para as estratégias de gestão para minimizar a rotatividade de pessoal e seus efeitos

\begin{tabular}{|c|c|c|c|c|c|c|c|c|c|}
\hline & \multirow[t]{2}{*}{ Estratégias de Gestão } & \multicolumn{2}{|c|}{$\begin{array}{c}\text { Cargo } \\
\text { gerencial }\end{array}$} & \multicolumn{2}{|c|}{$\begin{array}{l}\text { Número de } \\
\text { funcionários }\end{array}$} & \multicolumn{2}{|c|}{$\begin{array}{l}\text { Processo de } \\
\text { software } \\
\text { definido }\end{array}$} & \multicolumn{2}{|c|}{$\begin{array}{l}\text { Certificação de } \\
\text { melhoria de } \\
\text { processo }\end{array}$} \\
\hline & & Com & Sem & $<\mathbf{5 0}$ & $>\mathbf{5 0}$ & Sim & Parcial & Com & Sem \\
\hline 1 & $\begin{array}{l}\text { Adoção de política salarial e } \\
\text { de plano de carreira }\end{array}$ & 2 & 1 & 2 & 1 & 1 & 1 & 2 & 1 \\
\hline 2 & $\begin{array}{l}\text { Adoção de política de } \\
\text { benefícios e promoções por } \\
\text { desempenho }\end{array}$ & 1 & 2 & 1 & 2 & 2 & 3 & 1 & 2 \\
\hline 3 & $\begin{array}{l}\text { Documentação das atividades } \\
\text { do projeto para auxiliar os } \\
\text { novatos }\end{array}$ & 3 & 3 & 3 & 3 & 3 & 2 & 5 & 3 \\
\hline 4 & 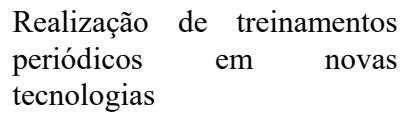 & 4 & 4 & 4 & 5 & 4 & 5 & 3 & 4 \\
\hline 5 & $\begin{array}{l}\text { Atividades realizadas em } \\
\text { pares para minimizar a saída } \\
\text { de um funcionário }\end{array}$ & 8 & 5 & 8 & 4 & 5 & 4 & 8 & 5 \\
\hline 6 & $\begin{array}{l}\text { Alternância de papéis para o } \\
\text { funcionário exercer mais de } \\
\text { uma função }\end{array}$ & 6 & 6 & 5 & 7 & 6 & 7 & 4 & 7 \\
\hline 7 & $\begin{array}{l}\text { Uso de entrevistas para avaliar } \\
\text { o risco antes da contratação }\end{array}$ & 5 & 7 & 7 & 6 & 7 & 8 & 6 & 6 \\
\hline 8 & $\begin{array}{l}\text { Realização de treinamentos no } \\
\text { início da contratação }\end{array}$ & 7 & 8 & 6 & 8 & 8 & 6 & 7 & 8 \\
\hline
\end{tabular}

A realização de treinamentos periódicos em novas tecnologias também foi bem considerada pelos respondentes das demais partes da amostra (linha 4). Comparando 
esse resultado com a literatura, em uma pesquisa das práticas relacionadas a recursos humanos e a rotatividade voluntária, Stovel e Bontis (2002) identificaram que o treinamento é uma das estratégias de gestão utilizadas para o gerenciamento eficaz da rotatividade dessas empresas.

\section{Ameaças à Validade}

A validade de um instrumento de pesquisa está relacionada ao nível de confiança de todo o processo de pesquisa. Os seguintes tipos de ameaças à validade são discutidos a seguir (Wohlin et al. 2000): conclusão, interna, construção e externa. A discussão das maneiras utilizadas para minimizar os efeitos de prováveis problemas que podem influenciar a validade dos resultados confere mais confiabilidade de que os resultados obtidos possam ser extrapolados para toda a população.

Quanto à validade de conclusão, a confiabilidade das respostas foi obtida através de elaboração disciplinada do questionário. Por exemplo, a realização do pré-teste teve papel importante para obter contribuições para melhorar a versão final do questionário. Além disso, o Coeficiente Alfa de Cronbach foi utilizado para avaliar a confiabilidade das respostas. Para a aplicação desse coeficiente, o questionário deve estar dividido e agrupado em questões que tratam de um mesmo aspecto e a amostra deve ser heterogênea (Cronbach e Shavelson 2004). O Coeficiente Alfa de Cronbach varia de 0 a 1 e um valor maior do que 0,6 representa uma confiabilidade aceitável. Os valores obtidos foram 0,6312 e 0,6509 para, respectivamente, as causas/efeitos da rotatividade e as estratégias de gestão.

Quanto à validade interna, a maneira como a pesquisa foi projetada e conduzida evita muitos dos problemas que afetam este tipo de validade. Por exemplo, as questões são objetivas e simples, e foram criadas de acordo com revisão prévia de trabalhos relacionados encontrados na literatura. No entanto, os resultados podem ter sido influenciados pela maneira como a amostra foi determinada (critério de amostragem não probabilística por conveniência), pois os respondentes são convidados a participar da pesquisa. Em geral, um respondente voluntário tem mais motivação para participar da pesquisa e predisposição para fornecer respostas positivas do que os demais indivíduos da população.

Quanto à validade de construção, o planejamento das etapas da pesquisa foi realizado com antecedência (conforme descrito na seção sobre a metodologia da pesquisa) e conduzido de acordo com o planejado para evitar os problemas decorrentes de procedimentos operacionais inadequados ou obscuros. Adicionalmente, as variáveis consideradas para as causas/efeitos e estratégias de gestão foram definidas claramente e, em especial, as causas e estratégias de gestão foram investigadas tanto por meio de questões em escala Likert quanto por meio de questões de múltipla escolha.

Quanto à validade externa, a dificuldade em generalizar os resultados obtidos pela análise estatística inferencial poderia estar relacionada com a amostra se os respondentes fossem profissionais em início de carreira porque não teriam experiência suficiente sobre rotatividade de pessoal para responder o questionário. A partir dos resultados obtidos das questões da seção do questionário sobre o respondente e a sua empresa atual (conforme descrito na subseção sobre a caracterização dos respondentes), é possível concluir que esse caso não foi identificado. 
Alguns resultados não podem ser generalizados para a população, pois não foi possível obter resultados estatisticamente significativos devido ao tamanho da amostra (67). Adicionalmente, devido à dificuldade de acesso às empresas brasileiras de desenvolvimento de software a amostra foi composta a partir de contatos profissionais, que ajudaram a disseminar o trabalho de pesquisa, solicitando a participação de profissionais da mesma empresa e também de outras empresas. Esse procedimento de composição da amostra pode ter gerado um viés (bias) com relação aos respondentes, uma vez que 50,75\% são tecnólogos, indicando que estes profissionais provavelmente são oriundos de empresas situadas nos estados de São Paulo e Paraná, nos quais existe maior quantidade de cursos dessa natureza. Como não foi objetivo identificar as empresas por razões de confidencialidade, não é possível fornecer uma análise da origem das empresas dos respondentes.

\section{Conclusões e Trabalhos Futuros}

Para as empresas da indústria de software é importante conhecer as causas e efeitos da rotatividade de pessoal e as possíveis estratégias de gestão que podem ser utilizadas para que a rotatividade não se torne um problema que não possa ser gerenciado. $O$ conhecimento sobre o fenômeno da rotatividade é estratégico para executivos, gerentes, líderes de projeto, entre outros profissionais que precisam tratar com recursos humanos.

Neste artigo foi apresentada uma pesquisa de opinião com o objetivo de identificar quais são as principais causas e efeitos da rotatividade de pessoal, e as estratégias de gestão para minimizar a rotatividade de pessoal e seus efeitos, segundo a opinião de profissionais de empresas brasileiras de desenvolvimento de software. A análise dos dados de 67 respondentes foi realizada por meio de análise estatística descritiva e análise estatística inferencial.

Os resultados indicaram que a falta de reconhecimento profissional, falta de política salarial, falta de comprometimento da organização e insatisfação decorrente de expectativa não alcançada estão entre as principais causas segundo os respondentes. Com relação aos efeitos, os mais selecionados pelos respondentes foram a sobrecarga dos funcionários que continuam no projeto, redução de produtividade até a substituição do funcionário e atrasos no cronograma do projeto. Esses resultados estão relacionados com a primeira questão de pesquisa (QP1) definida na Seção 3.

Os resultados para as causas apoiam fortes indicativos que os aspectos gerenciais são motivadores para a rotatividade de profissionais de empresas brasileiras de desenvolvimento de software. Além disso, os resultados também indicam outros aspectos que são importantes nesse contexto. As empresas devem estar atentas aos fatores que podem motivar a permanência do funcionário, como reconhecimento profissional, plano de carreira, promoção por desempenho e treinamento periódico. Resumindo, as empresas precisam fortalecer a sua política interna com relação aos seus funcionários.

Os gerentes de projeto devem estar conscientes dos fatores de estresse. Os resultados para os efeitos indicam o problema da sobrecarga de trabalho dos funcionários que continuam no projeto. Além disso, o estresse também pode ser provocado pela insatisfação, estilo gerencial inadequado e pelo ambiente de trabalho. 
Portanto, o contexto organizacional pode influenciar a intenção de rotatividade de pessoal em empresas brasileiras de desenvolvimento de software.

Com relação às estratégias de gestão (QP2), as seguintes estão entre as principais segundo os respondentes: adoção de política salarial e de plano de carreira, adoção de política de benefícios e promoções por desempenho, documentação das atividades do projeto para auxiliar os novatos e realização de treinamentos periódicos. Em especial, a documentação (e a gestão do conhecimento no sentido mais amplo) é útil na aceleração do aprendizado de um novo funcionário e consequentemente pode minimizar os efeitos da rotatividade de pessoal. As empresas brasileiras de desenvolvimento de software devem acompanhar com atenção o comportamento da taxa de rotatividade e definir estratégias de gestão adequadas com o objetivo de diminuir o risco e o dano causado ao projeto.

O fenômeno da rotatividade de pessoal no contexto de empresas brasileiras de desenvolvimento de software merece ser mais bem investigado. Alguns dos trabalhos que podem dar continuidade a esta pesquisa são resumidos a seguir:

- Entrevistar profissionais de empresas brasileiras de desenvolvimento de software para investigar em profundidade as intenções para sair da empresa e o que poderia ser feito pela empresa que seria uma motivação para a permanência de seu funcionário.

- Investigar diferentes estilos gerenciais e a relação com a rotatividade de pessoal, por exemplo, por meio de um estudo de caso (análise de um único ou de poucos casos).

- Realizar a pesquisa de opinião com uma amostra maior, uma vez que os dados foram insuficientes para fazer algumas inferências (principalmente na comparação entre partes da amostra).

- Avaliar os efeitos do emprego de novas estratégias de gestão para minimizar a rotatividade e seus efeitos em relação a dados históricos de taxas de rotatividade em projetos de desenvolvimento de software.

- Avaliar o custo financeiro da rotatividade para as empresas de desenvolvimento de software.

- Investigar o perfil do profissional de desenvolvimento de software com intenção de rotatividade.

A pesquisa de opinião apresentada neste artigo beneficia as empresas da indústria de software e fornece suporte para a realização de novas investigações. Dessa maneira, os resultados apresentados representam avanços para o estado da arte relacionado com a rotatividade de pessoal. 


\section{Referências}

Abbasi, S. M. and Hollman, K. W. (2000) Turnover: The real bottom line. Public Personnel Management, v. 29, n. 3, p. 333-342.

Ahuja, M. K., Chudoba, K. M., Kacmar, C. J., McKnight, D. H. and George, J. F. (2007) IT road warriors: balancing work-family conflict, job autonomy, and work overload to mitigate turnover intentions. MIS Quarterly, v. 31, n. 1, p. 1-17.

Ang, S. and Slaughter, S. (2004) Turnover of information technology professionals: the effects of internal labor market strategies. ACM SIGMIS Database, v. 35, n. 3, p. 1127.

Cai, J., Wang, Y. and Zhang, H. (2015) Research on the Effects of EAPs on Turnover Intentions. In Proceedings of the International Conference on Service Systems and Service Management, Guangzhou, China, IEEE, p. 1-5.

Calisir, F., Gumussoy, C. A. and Iskin, I. (2011) Factors affecting intention to quit among IT professionals in Turkey. Personnel Review, v. 40, n. 4, p. 514-533.

Carvalho, W. C. S. (2012) Análise dos Efeitos do Turnover na Produtividade de Processos de Software Tradicionais e Híbridos, Dissertação, Programa de PósGraduação em Ciência da Computação, PPGCC, Faculdade de Computação, FACOM, Universidade Federal de Uberlândia, UFU.

Chang, C. L. -H. (2010) The Study of the Turnover of MIS professionals - The Gap Between Taiwanese and US Societies. International Journal of Information Management, v. 30, n. 4, p. 301-314.

Chiavenato, I. (2014). Gestão de Pessoas. Manole, 4. ed. 512 p.

Chowdary, E., Deepak, K. A., Devi, D., Mounika, S., Venkatramaphanikumar and Kishore, K. V. K. (2016) Ensemble Classification Technique to Detect Stress in ITProfessionals. In: Proceedings of the International Conference on Inventive Computation Technologies, Coimbatore, India, IEEE, v. 3, p. 1-6.

Cronbach, L. J. and Shavelson, R. J. (2004) My current thoughts on coefficient alpha and successor procedures. Educational and psychological measurement, v. 64, n. 3, p. 391-418.

Felps, W., Mitchell, T. R., Hekman, D. R., Lee, T. W., Holtom, B. C. and Harman, W. S. (2009) Turnover contagion: How coworkers' job embeddedness and job search behaviors influence quitting. Academy of Management Journal, v. 52, n. 3, p. 545561.

Ferratt, T. W., Agarwal, R., Brown, C. V. and Moore, J. E. (2005) IT human resource management configurations and IT turnover: Theoretical synthesis and empirical analysis. Information Systems Research, v. 16, n. 3, p. 237-255.

Ghosh, P., Satyawadi, R., Joshi, J. P. and Shadman, M. (2013) Who Stays with You? Factors Predicting Employees Intention to Stay. International Journal of Organizational Analysis, v. 21, n. 3, p. 288-312. 
Grossman, T., Fitzmaurice, G. and Attar, R. A. (2009) Survey of Software Learnability: Metrics, Methodologies and Guidelines. In: Proceedings of the SIGCHI Conference on Human Factors in Computing Systems, Boston, MA, USA, ACM, p. 649-658.

Johnson, J. T., Griffeth, R. W. and Griffin, M. (2000) Factors discriminating functional and dysfunctional salesforce turnover. Journal of business \& industrial marketing, v. 15 , n. 6, p. 399-415.

Joseph, D., Ng, K. -Y., Koh, C. and Ang, S. (2007) Turnover of information technology professionals: a narrative review, meta-analytic structural equation modeling, and model development. MIS Quarterly, v. 31, n. 3, p. 547-577.

Kaptein, M. C., Nass, C. and Markopoulos, P. (2010) Powerful and Consistent Analysis of Likert-type Ratingscales. In Proceedings of the SIGCHI Conference on Human Factors in Computing Systems, Atlanta, Georgia, USA, ACM, p. 2391-2394.

Kitchenham, B. (2004) Procedures for performing systematic reviews. Joint Technical Report, Keele University and National ICT Australia Ltd.

Korunka, C., Hoonakker, P. and Carayon, P. (2008) Quality of working life and turnover intention in information technology work. Human Factors and Ergonomics in Manufacturing \& Service Industries, v. 18, n. 4, p. 409-423.

Kuhrmann, M. and Munch, J. (2016) When Teams Go Crazy: An Environment to Experience Group Dynamics in Software Project Management Courses. In Proceedings of the IEEE/ACM International Conference on Software Engineering Companion, Austin, TX, USA, ACM, p. 412-421.

Lim, S. (2008) Job satisfaction of information technology workers in academic libraries. Library \& Information Science Research, v. 30, n. 2, p. 115-121.

Liu, X. (2008) Study on decision support system of employee turnover risk management. International Journal of Business and Management, v. 3, n. 8, p. 7380 .

Longenecker, C. O. and Scazzero, J. A. (2003) The turnover and retention of IT managers in rapidly changing organizations. Information Systems Management, v. 19 , n. 4, p. $58-63$.

Mikropoulos, T. A. and Natsis, A. (2011) Educational virtual environments: A ten-year review of empirical research. Computers \& Education, v. 56, n. 3, p. 769-780.

Moore, J. E. (2000) One Road to Turnover: An Examination of Work Exhaustion in Technology Professionals. MIS Quarterly., v. 24, n. 1, p. 141-168.

Muhammad, M. R., Nasir, M. M., Hameed, U. K. and Ikram, A. (2015) Impact of Stress on Software Engineers Knowledge Sharing and Creativity [A Pakistani Perspective]. International Journal of Data Mining Techniques and Applications, v. 4, p. 35-39.

O'Connell, M. and Kung, M. -C. (2007) The Cost of Employee Turnover. Industrial Management, v. 49, n. 1, p. 14-19.

Petrillo, F., Spritzer, A. S., Freitas, C. D. S. and Pimenta, M. (2011) Interactive Analysis of Likert Scale Data Using a Multichart Visualization Tool. In Proceedings of the Brazilian Symposium on Human Factors in Computing Systems and Latin American 
Conference on Human-Computer Interaction, Porto Alegre, RS, Brazil, Brazilian Computer Society, p. 358-365.

Porter, L. W. and Steers, R. M. (1973) Organizational, work, and personal factors in employee turnover and absenteeism. Psychological Bulletin, v. 80, n. 2, p. 151-176.

Ress, A. P. M., Moraes, R. O. and Nakano, D. N. (2010) O uso da gestão de conhecimento como fator de moderação do impacto da alta rotatividade da equipe de TI no desempenho dos projetos. In Anais do Encontro Nacional de Engenharia de Produção, São Carlos, SP, Brasil.

Rong, J., Hongzhi, L., Jiankun, Y., Tao, F., Chenggui, Z. and Junlin, L. (2009) A model based on information entropy to measure developer turnover risk on software project. In Proceedings of the IEEE International Conference on Computer Science and Information Technology, Beijing, China, ACM, p. 419-422.

Silva, G. L. R. (2001) Controle de turnover: como prevenir e demitir com responsabilidade. Qualitymark. 80 p.

Slyngstad, O. P. N., Gupta, A., Conradi, R., Mohagheghi, P., Rønneberg, H. and Landre, E. (2006) An Empirical Study of Developers Views on Software Reuse in statoil ASA. In Proceedings of the ACM/IEEE International Symposium on Empirical Software Engineering, Rio de Janeiro, Brazil, ACM, p. 242-251.

Stovel, M. and Bontis, N. (2002) Voluntary turnover: knowledge management--friend or foe? Journal of intellectual Capital, v. 3, n. 3, p. 303-322.

Thatcher, J. B., Liu, Y., Stepina, L. P., Goodman, J. M. and Treadway, D. C. (2006) IT Worker Turnover: An Empirical Examination of Intrinsic Motivation. ACM SIGMIS Database, v. 37, n. 2-3, p. 133-146.

Wang, X., Wang, H., Zhang, L. and Cao, X. (2011) Constructing a decision support system for management of employee turnover risk. Information Technology and Management, v. 12, n. 2, p. 187-196.

Wohlin, C., Runeson, P., Höst, M., Ohlsson, M. C., Regnell, B. and Wesslén, A. (2012) Experimentation in software engineering. Springer, $236 \mathrm{p}$.

Yu, Y., Benlian, A. and Hess, T. (2010) Explaining Perceived Turnover in Open Source Software Projects based on Hygiene Factors. In Proceedings of the Americas Conference on Information Systems, Lima, Peru. Paper 152.

Zhang, X., Ryan, S. D., Prybutok, V. R. and Kappelman, L. (2012) Perceived obsolescence, organizational embeddedness, and turnover of it workers: an empirical study. ACM SIGMIS Database, v. 43, n. 4, p. 12-32.

Zhang, Z. Y., Liu, T. and Chen, Y. W. (2016) The Impact of Work-Family Interface on Turnover Intention of IT R D Personnel: A Mediator Role of Psychological Contract. In Proceedings of the IEEE International Conference on Industrial Engineering and Engineering Management. Bali, Indonesia, IEEE, p 1737-1741.

Zhou, J., Wang, Q., Tsai, S. B., Xue, Y. and Dong, W. (2016) How to Evaluate the Job Satisfaction of Development Personnel. IEEE Transactions on Systems, Man, and Cybernetics: Systems, v. 99, p 1-8. 